\title{
Experiences of Online Co-creation with End Users of Cloud Services
}

\author{
Kaarina Karppinen ${ }^{1}$, Kaisa Koskela ${ }^{1}$, Camilla Magnusson ${ }^{2}$, and Ville Nore $^{2}$ \\ ${ }^{1}$ VTT Technical Research Centre of Finland, Kaitoväylä 1, 90570 Oulu, Finland \\ \{kaarina. karppinen, kaisa. koskela\} @vtt.fi \\ ${ }^{2}$ F-Secure Ltd. Tammasaarenkatu 7, 00180 Helsinki, Finland \\ \{camilla.magnusson, ville.nore\}@f-secure.com
}

\begin{abstract}
This paper describes an online co-creation study done via an online co-creation platform Owela as well as shares industrial experiences and lessons learnt about the study. The Owela study was conducted in order to provide a deeper understanding of users' perceptions of cloud services and their security. By utilising the online co-creation platform it was possible to get quick and easy contact to geographically distributed cloud service users. For the company Owela offered an efficient way to apply online user participation while for the end users Owela enabled convenient participation in various co-creation activities regardless of time and place. As an end result of the study the voice of the cloud service users was turned into several new business ideas.
\end{abstract}

Keywords: Online co-creation, Owela, Cloud services, End users.

\section{Introduction}

Cloud phenomenon is one of the main global trends washing through the ICT industry [1]. Today the cloud is also reality in consumers' life as typical web users use cloud services daily whether they know it or not [2]. This novel way of offering software, platforms and infrastructure as a service via the internet opens up new possibilities and advantages for companies such as F-Secure, a provider of consumer cloud security and storage solutions.

In order to create new business opportunities within the cloud security domain there is a need to understand what the user perception of cloud services and their security is, and how it is formed. However, reaching geographically distributed cloud service end users via traditional user involvement methods is challenging. To overcome this challenge, we used an approach where co-creation with cloud service end users was done via an online co-creation platform Owela (http://owela.vtt.fi/owela/introduction). Owela is an online living lab that builds on social media features for co-creation activities and open innovation [3]. It was launched in April 2007 and is administrated by VTT Technical Research Centre of Finland. The conducted four week-long Owela study involved a use of various online co-creation tools enabled by the platform such as discussions, commenting, blog posting, idea posting, and chat sessions. In this paper we are presenting how the study was conducted as well as sharing experiences and lessons learnt from it. 


\section{Background}

Advances in information and communication technologies give companies new opportunities to include users to their processes [3]. According to Swahney et al. [4] online based virtual environments allow a company to engage a larger number of end users without significant compromises on the richness of the interaction. Virtual environment also increase the speed and persistence of user engagement and the episodic and one way interaction with end users can be transformed into a continuous dialogue [4]. Through online collaboration users can also be involved in co-creation activities regardless of time and place.

\section{Description of the Owela Study}

The purpose of the Owela study was to discuss with the cloud service users about how they actually use the services and how the existing services could be improved as well as to co-create ideas for new services. The participants were selected based on their responses to an online survey carried out in June 2010 [2]. A total of 128 end users were invited to join the Owela workspace. From them 47 registered within one week from the invitation. Also 4 representatives from F-Secure participated actively in Owela during the whole study. The company representatives were separately identified so that the users were all the time aware which actions were made by other users and which by the company representatives. In addition, two VTT researchers facilitated the online co-creation. Table 1 gives more information about the study.

Table 1. Details of the Owela study

\begin{tabular}{|l|l|}
\hline Length & 4 weeks (24.9.-22.10.2010) \\
\hline Participants & $\begin{array}{l}\text { 47 end users } \\
\text { 4 company representatives } \\
\text { 2 researchers }\end{array}$ \\
\hline $\begin{array}{l}\text { Tools for } \\
\text { communication }\end{array}$ & $\begin{array}{l}\text { Discussions (320 postings) } \\
\text { Blogs (60 comments) } \\
\text { Idea posting and commenting (14 ideas, } 80 \text { comments) } \\
\text { Chat sessions (5 x 2 hour sessions) }\end{array}$ \\
\hline $\begin{array}{l}\text { Schedule for } \\
\text { participation }\end{array}$ & $\begin{array}{l}\text { Schedule for participation was optional (users could participate } \\
\text { anytime) except for the chat sessions for which the time was announced } \\
\text { beforehand }\end{array}$ \\
\hline $\begin{array}{l}\text { Motivation and } \\
\text { rewarding }\end{array}$ & $\begin{array}{l}\text { Activity points and rewards } \\
\text { Active participation of F-Secure and VTT representatives } \\
\text { Weekly email reminders }\end{array}$ \\
\hline
\end{tabular}

In the Owela workspace designed for the study, several specific features were used to achieve continuous communication between the end users and company representatives. First of all, Owela enabled active online discussion. The discussions revolved around predefined theme questions which were given to the participants each week. The participants answered these questions and were able to comment each other's answers thus creating discussion. Also F-Secure's and VTT's representatives 
were actively involved in the discussions to steer them and to probe emerging interesting topics. Secondly, in the Owela blog section users could write down their daily experiences with usage of cloud services according to each week's theme. The participants were encouraged to e.g. share negative and positive experiences with cloud services, compare different services, consider their network identity, and talk about situations that made them feel insecure. Thirdly, the participants had the chance of posting ideas about new cloud services. When posting an idea the participants were asked to write down both the idea that they had in mind and the problem that the idea would solve. This way also other participants had the opportunity to give solution ideas for the stated problems. Finally, five two-hour chat sessions were organized. The purpose of the chat sessions was to promote the direct and synchronized communication between the participants and the company representatives.

Activation and motivation of participants was considered very important in order to receive as good research results as possible. The primary way of activation was the active company representative participation in the discussions by asking questions and commenting the participants' postings. Another way of activation was to send weekly emails to the participants. The emails included current issues such as the theme and tasks for the week as well as a reminder of the chat session schedule and collecting the activity points. The third way to activate the participants was rewarding. The participants earned activity points for their actions at the Owela workspace and these points could be used as lottery tickets in a weekly movie ticket lottery as well as for earning a product gift in the end of the study.

\section{Experiences and Lessons Learned}

From F-Secure's point of view, online co-creation was seen to be a fruitful new way of interacting with end users. Compared to traditional end user research methods such as focus groups, interviews and usability testing used by F-Secure, this method turned out to be much more flexible, which was a benefit to both the end users and the company. It allowed participating end users to give their input whenever they had a few minutes of extra time, without having to leave their home or office. For F-Secure, it enabled defining various research goals during the study, reacting to feedback, and modifying the goals accordingly. Moving focus to new topics that may emerge from the user community during the study is usually hard to do with traditional, often quite rigid forms of end user research. Online co-creation thus enabled a continuous and rich dialogue between the company and end users.

However, it is important to note that Owela or any other online co-creation tool alone cannot ensure the success of a consumer research project. In order to reach the goals, commitment from the company as well as skilful facilitators, for keeping the discussions going and stimulating participants, were essential. Key factors for achieving success were: 1. active participation of all the parties in online conversations, 2. maintaining an active and encouraging atmosphere throughout the whole duration of the study, which motivated users to login frequently, and 3 . enabling users to freely share their creative thoughts without the fear of ridicule or pressure to conform. 
For F-Secure, the study produced immediately actionable results. It provided valuable insights into consumers' usage and perceptions of cloud services. It also generated 14 new consumer product ideas, which were entered into F-Secure's idea funnel for further development and evaluation. Some examples of the general themes of the product ideas are 1) providing a more secure online shopping and browsing experience, 2) allowing users to control their privacy online, and 3) securing users' cloud based data in various ways. Furthermore, the study provided a way for F-Secure to obtain feedback on upcoming products from mainstream end users, who may not have enough interest in technology to take part in traditional beta testing communities or company-specific, often quite technical, discussion forums.

\section{Conclusions}

The online co-creation study conducted via Owela provided F-Secure with a deeper understanding of users' perceptions of cloud services and their security. By utilising the online co-creation space it was possible to get quick and easy contact to geographically distributed cloud service users. Owela acted as a continuous communication channel between the company representatives and the cloud service users. Active online participation by all parties and energetic and encouraging atmosphere created in Owela were the key factors for achieving successful results. For F-Secure Owela offered an efficient way to apply online user participation while for the users Owela enabled participation in various co-creation activities anytime anywhere. The voice of the cloud service users was turned into several new business ideas that are further explored within the company.

\section{References}

1. Dikaiakos, M.D., Katsaros, D., Mehra, P., Pallis, G., Vakali, A.: Cloud Computing: Distributed Internet Computing for IT and Scientific Research. IEEE Internet Computing 13(5), 10-13 (2009), doi:10.1109/MIC.2009.103

2. Karppinen, K., Koskela, K., Koivumäki, T.: Usage of Cloud Services - A Survey for Consumers in USA, Japan and Finland. In: 1st International Conference on Cloud Computing and Services Science - CLOSER 2011, Noordwijkerhout, The Netherlands, May 7-9, pp. 305-308 (2011)

3. Näkki, P., Antikainen, M.: Online Tools for Co-design: User Involvement through the Innovation Process. In: The Workshop: New Approaches to Requirements Elicitation \& How Can HCI Improve Social Media Development?, NordiCHI, Lund, Sweden, October 18-22 (2008)

4. Di Gangi, P.M., Wasko, M.M., Hooker, R.E.: Getting Customers' Ideas to Work for You: Learning from Dell How to Succeed with Online User Innovation Communities. MIS Quarterly Executive 9(4), 213-228 (2010)

5. Swahney, M., Verona, G., Prandelli, E.: Collaborating to Create: the Internet as a Platform for Customer Engagement in Product Innovation. Journal of Interactive Marketing 19(4), 4 17 (2005) 